\title{
Delivery of Pharmacogenetic Testing with or without Medication Therapy Management in a Community Pharmacy Setting
}

\author{
Susanne B Haga (D) \\ Rachel Mills $\mathbb{D}$ \\ Jivan Moaddeb \\ Yiling Liu \\ Deepak Voora
}

Center for Applied Genomics \& Precision Medicine, Duke University School of Medicine, Durham, NC, 27708, USA
Correspondence: Susanne B Haga

Email Susanne.haga@duke.edu
Objective: The delivery of pharmacogenetic (PGx) testing has primarily been through clinical and hospital settings. We conducted a study to explore the feasibility of delivering PGx testing through community pharmacies, a less-studied setting.

Methods: We conducted a cluster randomized trial of community pharmacies in North Carolina through two approaches: the provision of PGx testing alone or PGx testing with medication therapy management (MTM).

Results: A total of 150 patient participants were enrolled at 17 pharmacies and reported high satisfaction with their testing experience. Participants in the PGx plus MTM arm were more likely to recall a higher number of results $(\mathrm{p}=0.04)$ and more likely to clearly understand their choices for prevention or early detection of side effects $(\mathrm{p}=0.01)$. A medication or dose change based on the PGx results was made for $8.7 \%$ of participants.

Conclusion: Limited differences were observed in the provision of PGx testing as a standalone test or combined with MTM. A limited number of treatment changes were made based on PGx test results. Patient acceptance of PGx testing offered through the community pharmacy was very high, but the addition of MTM did not impact patientreported perceptions about PGx testing or medication adherence.

Keywords: pharmacy, pharmacogenetic testing, feasibility, patient experience

\section{Introduction}

Pharmacogenetic (PGx) testing is a cross-specialty application with a high likelihood of detecting an actionable result for many commonly prescribed medications. Unlike other clinical tests where test utilization is driven by specific clinical indications, PGx testing has several options for delivery with variability in clinical settings, types of clinical providers, and timing including pre-emptively, at the point-of-care when treatment is indicated, or post-treatment. With increasing attention to the implementation and delivery of PGx testing, identification of the barriers and facilitators in different clinical settings can help promote widespread integration of testing across specialties and practice settings. In addition, consideration of patient experiences can inform the development of strategies and resources to optimize comprehension of results, medication compliance, and sharing of results with providers.

To date, most of the PGx implementation studies and initiatives have been launched in specialty clinics or hospital settings. While the prescriber's role in 
initiating testing and adjusting treatment based on test results is often a focus of these studies, in some programs, the pharmacist also plays a central role, such as operating a PGx consultation service, and/or serving as a liaison between the physician/clinic, testing laboratory, and sometimes, the patient. One critical role of the pharmacist is to assist with interpretation of results and convey the recommended changes in medication selection or dosing to the prescriber. Studies have reported a lack of pharmacist knowledge about PGx, but many efforts have been made to increase PGx content in pharmacy curricula and prepare new and practicing pharmacists to play a leading role in the use of PGx testing, seemingly outpacing similar educational efforts for prescribers.

An alternative approach to the delivery of PGx testing is in the community pharmacy setting. In this setting, testing can be offered by pharmacists to patients who are filling prescriptions for medications with known PGx interactions. Laboratory test ordering by pharmacists is overseen by state regulations, either as authorized providers or through a collaborative practice agreement with a physician(s). Similarly, pharmacists' authority to initiate or modify prescriptions is limited to select medications, minor health conditions, and/or existence of collaborative practice agreements with a physician(s). However, a large majority of community pharmacists are still not able to make even these limited modifications. PGx testing may also be integrated into medication therapy management (MTM) provided by the pharmacist to consider both drug-drug and drug-gene interactions.

Although many factors can impact patient attitudes, community pharmacists have generally been considered as a trusted resource and often have long-term relationships with patients, providing increasingly more services with demonstrated patient benefits or equivalent to standard of care. Furthermore, the inclusion of pharmacists on provider teams and expanded clinical roles have demonstrated favorable patient outcomes. The delivery of PGx testing in this setting has been considered but not extensively investigated. Here we report the findings of our study to assess the feasibility of delivering PGx testing in a community pharmacy setting, either as a standalone test or delivered through an MTM session. We collected data from both participating patients and pharmacists about their experiences, as this was likely a unique experience for one or both parties. In addition, to ascertain the impact of PGx testing, we collected patient data regarding medication changes and adherence. Our findings can help inform delivery of PGx testing in community pharmacy settings and the role of pharmacists to facilitate integration of PGx results into therapeutic decisions.

\section{Methods Study Overview}

Details of this study design have been previously described. In summary, a cluster randomized trial was conducted whereby community pharmacies were randomized to provide PGx testing (control arm) or PGx testing with MTM (intervention). In addition to having a recent $(<1$ year active) prescription of one of the specified medications (listed at bottom of Table 1), patient participants had to be 18 years of age or older to participate; patients were ineligible to participate if they previously underwent PGx testing for one of the targeted genes or had MTM services in the previous year. Buccal swab samples were collected from patients at the pharmacy and sent to Pathway Genomics for testing. Results for five genes (CYP2C19, CYP2C9, CYP2D6, VKORC1, and SLCO1B1) associated with the ten eligible medications (see) were returned to patients. The study protocol was approved by the Institutional Review Board of the Duke University Health System (Pro00068552) and registered in ClincalTrials.gov (NCT02937545). All participants were informed about the purpose of the study and written consent obtained prior to study commencement. The study was conducted in accordance with the Declaration of Helsinki.

Prior to enrolling patients in the study, pharmacists were required to attend a mandatory training session on PGx (continuing education credits provided). Informed consent was also obtained from pharmacists to collect survey data on knowledge and experiences. Participating patients and pharmacists were surveyed prior to and after the study. Data from pharmacist surveys and interviews regarding their experiences and will be published separately.

\section{Pharmacist Sites}

Thirty-six pharmacists at 22 independent community pharmacies in North Carolina participated in the study. Sites were selected through connections with independent pharmacies and contacting independent pharmacies listed in the National Community Pharmacist Association in North Carolina. The 22 sites were equally randomized to one of the two study arms (PGx only or PGx plus MTM). 
Table I Characteristics of Participants Based on Pharmacist Chart Review Data and Pre/Post-Study Participant Surveys (Completed Both the Pre-Testing and Post-Testing Surveys)

\begin{tabular}{|c|c|c|c|c|c|}
\hline \multicolumn{2}{|l|}{ Characteristic } & \multicolumn{2}{|c|}{$\begin{array}{l}N=150 \text { (\%) (Pharmacist Chart } \\
\text { Review) }\end{array}$} & \multicolumn{2}{|c|}{$\begin{array}{l}\text { N=38 (\%) (Patient-Reported Pre/ } \\
\text { Post-Testing Survey) }\end{array}$} \\
\hline & & \multirow{2}{*}{$\begin{array}{l}\begin{array}{l}\text { PGx Only } \\
(\mathbf{N}=67)\end{array} \\
33(49.3 \%)\end{array}$} & \multirow{2}{*}{$\begin{array}{l}\begin{array}{l}\text { PGx+MTM } \\
(\mathbf{N}=83)\end{array} \\
28(33.7 \%)\end{array}$} & \multirow{2}{*}{$\begin{array}{l}\text { PGx Only } \\
(\mathbf{N}=\mathbf{2 1}) \\
9(42.9 \%)\end{array}$} & \multirow{2}{*}{$\begin{array}{l}\mathbf{P G x + M T M} \\
(\mathbf{N}=17)\end{array}$} \\
\hline Sex & Male & & & & \\
\hline & Female & $34(50.7 \%)$ & 55 (66.3\%) & $12(57.1 \%)$ & $12(70.6 \%)$ \\
\hline \multirow[t]{7}{*}{ Age group } & $18-29$ & $5(7.5 \%)$ & $2(2.4 \%)$ & $2(9.5 \%)$ & 0 \\
\hline & $30-39$ & $5(7.5 \%)$ & $4(4.8 \%)$ & $3(14.3 \%)$ & $2(11.8 \%)$ \\
\hline & $40-49$ & $12(17.9 \%)$ & 12 (14.5\%) & $3(14.3 \%)$ & 5 (29.4\%) \\
\hline & $50-59$ & $14(20.9 \%)$ & II (13.3\%) & $5(23.8 \%)$ & I (5.9\%) \\
\hline & $60-69$ & $15(22.4 \%)$ & $17(20.5 \%)$ & $5(23.8 \%)$ & $2(11.8 \%)$ \\
\hline & 70 years or older & $16(23.9 \%)$ & $37(44.6 \%)$ & $2(9.5 \%)$ & $7(41.2 \%)$ \\
\hline & Unknown & 0 & 0 & I (4.8\%) & 0 \\
\hline \multirow[t]{3}{*}{ Ethnicity } & Hispanic or Latino & $2(3 \%)$ & 0 & 0 & I (5.9\%) \\
\hline & Not Hispanic or Latino & 0 & 0 & 20 (95.2\%) & $16(94.1 \%)$ \\
\hline & Unknown & $65(97.0 \%)$ & $83(100 \%)$ & I (4.8\%) & 0 \\
\hline \multirow[t]{5}{*}{ Race } & Black or African American & $2(3 \%)$ & $7(8.4 \%)$ & I (4.8\%) & I (5.9\%) \\
\hline & White & 61 (91\%) & $74(89.2 \%)$ & 19 (90.5\%) & $16(94.1 \%)$ \\
\hline & Asian & I (1.5\%) & I (1.2\%) & 0 & 0 \\
\hline & More than one race & I (1.5\%) & 0 & I (4.8\%) & 0 \\
\hline & Other/Unknown & $2(3 \%)$ & $\mathrm{I}(\mathrm{l} .2 \%)$ & 0 & 0 \\
\hline \multirow{6}{*}{$\begin{array}{l}\text { Highest Level of School } \\
\text { Completed }\end{array}$} & 9-12th grade, no diploma & - & - & I (4.8\%) & 0 \\
\hline & High school grad or equivalent (GED) & - & - & $2(9.5 \%)$ & I (5.9\%) \\
\hline & Some college, no degree & - & - & $5(23.8 \%)$ & $3(17.6 \%)$ \\
\hline & Associate's degree & - & - & $3(14.3 \%)$ & $2(11.8 \%)$ \\
\hline & Bachelor degree & - & - & $6(28.6 \%)$ & $7(41.2 \%)$ \\
\hline & Graduate or professional degree & - & - & $4(19.0 \%)$ & $4(23.5 \%)$ \\
\hline \multirow[t]{7}{*}{ Health insurance* } & Private health insurance & - & - & $10(47.6 \%)$ & $9(52.9 \%)$ \\
\hline & Medicare & - & - & $9(42.9 \%)$ & $10(58.8 \%)$ \\
\hline & Medi-gap & - & - & 0 & $4(23.5 \%)$ \\
\hline & Medicaid & - & - & $2(9.5 \%)$ & $2(11.8 \%)$ \\
\hline & $\begin{array}{l}\text { Military health care (TRICARE/VA/ } \\
\text { CHAMP-VA) }\end{array}$ & - & - & 0 & $\mathrm{I}(5.9 \%)$ \\
\hline & State-sponsored health plan & - & - & 4 (19.0\%) & I (5.9\%) \\
\hline & $\begin{array}{l}\text { Single service (eg dental, vision, } \\
\text { prescription) }\end{array}$ & - & - & I (4.8\%) & $2(11.8 \%)$ \\
\hline
\end{tabular}


Table I (Continued).

\begin{tabular}{|c|c|c|c|c|c|}
\hline \multicolumn{2}{|l|}{ Characteristic } & \multicolumn{2}{|c|}{$\begin{array}{l}\mathrm{N}=150(\%) \text { (Pharmacist Chart } \\
\text { Review) }\end{array}$} & \multicolumn{2}{|c|}{$\begin{array}{l}\text { N=38 (\%) (Patient-Reported Pre/ } \\
\text { Post-Testing Survey) }\end{array}$} \\
\hline & & $\begin{array}{l}\text { PGx Only } \\
(\mathrm{N}=67)\end{array}$ & $\begin{array}{l}P G x+M T M \\
(N=83)\end{array}$ & $\begin{array}{l}\text { PGx Only } \\
(\mathrm{N}=2 \mathrm{I})\end{array}$ & $\begin{array}{l}P G x+M T M \\
(N=17)\end{array}$ \\
\hline \multirow[t]{10}{*}{ Prescribed Drug } & Aripiprazole & 7 (10.4\%) & $13(15.7 \%)$ & - & - \\
\hline & Celecoxib & $5(7.5 \%)$ & $2(2.4 \%)$ & - & - \\
\hline & Citalopram & 12 (I7.9\%) & 15 (18.1\%) & - & - \\
\hline & Clopidogrel & $4(6.0 \%)$ & $12(14.5 \%)$ & - & - \\
\hline & Metoprolol & 18 (26.9\%) & $25(30.1 \%)$ & - & - \\
\hline & Nortriptyline & II (16.4\%) & $0(0 \%)$ & - & - \\
\hline & Paroxetine & $3(4.5 \%)$ & $\mathrm{I}(1.2 \%)$ & - & - \\
\hline & Simvastatin & $4(6.0 \%)$ & 14 (I6.9\%) & - & - \\
\hline & Warfarin & $3(4.5 \%)$ & $0(0 \%)$ & - & - \\
\hline & Carisoprodol & $0(0 \%)$ & I (I.2\%) & - & - \\
\hline
\end{tabular}

Note: *Indicates more than one answer choice may be selected and therefore, total is more than $100 \%$.

Sites without private counseling space were not eligible to be randomized to the PGx plus MTM arm and automatically assigned to the PGx only arm. A total of seven pharmacies (and 13 pharmacists) dropped out or were withdrawn due to low enrollment; five of those pharmacies were unable to enroll any participants. Seven of the remaining 15 pharmacies were in the PGx only arm and eight in the PGx plus MTM arm.

\section{Patient Surveys}

Patients who consented to PGx testing were invited to complete two online surveys: one at baseline and one after test results had been communicated. Patients were asked to complete the baseline survey following provision of the sample for testing; the follow-up survey was sent to patients after test results were available. The baseline survey collected demographic data, prior knowledge about PGx, medication beliefs through the Beliefs about Medicine Questionnaire (BMQ), and self-reported medication adherence. The follow-up survey gathered data on satisfaction with the testing experience in a community pharmacy setting, perceived value of testing, comprehension of test result, self-reported medication adherence, information-sharing, and an adapted assessment to measure the psychological impact of PGx results. As patient identifiers were not linked to the surveys to protect patient privacy, PGx test results could not be linked to survey responses to confirm responses. All surveys were administered through REDCap, a secure web application for building and administering online surveys.

\section{LogBook}

Pharmacists were provided with a folder for each participant enrolled from their pharmacy to document and record information about each participant. Specifically, pharmacists were asked to complete a form indicating dates of key testing activities (eg, consent obtained, physician authorization obtained, testing completed) as well as use of print or electronic educational materials provided by the study team to assist the pharmacist in discussing PGx testing, test results and whether a change in prescription based on the test results was made. We asked pharmacists to keep track of their activities related to the study, particularly interactions with each participant and their provider to assess feasibility of delivering PGx testing in a community pharmacy setting on a log sheet. In addition to the purpose of the interaction, pharmacists were asked to record the date, start and stop times, and mode of communication (in-person, phone, fax, email) for each interaction with each participant or participant's provider.

\section{Chart Review}

Pharmacy adherence data were collected six months after test results were communicated for the enrolled participant 
and two matched controls. Each participating pharmacy identified two controls per each participant enrolled (2:1) and matched on drug, age and gender. Time on treatment, medication changes (dose/drug selection), and refill history (adherence) data were requested to be submitted with the six-month follow-up data from each pharmacy along with some demographic data based on chart reviews for participants and controls.

\section{Data Analysis}

Summary statistics were calculated for all data points collected from the logbook, chart review, and the survey questions. We tested for relationships between participant demographic variables and outcomes as well as survey responses. For categorical variables, we used Fisher's exact test and for continuous variables (eg, age), we used the exact Wilcoxon rank sum test. To test if the demographic characteristics of the participants were independent of their tendency to complete both the pre- and posttesting survey, Fisher's exact test was applied for race and gender (categorical variables), and exact Wilcoxon rank sum test for age (continuous variable). To determine if medication adherence behavior changed after testing, a McNemar's Chi-squared test was applied with continuity correction. To detect changes in participants' attitudes toward medications before and after the testing using the BMQ scale, exact Wilcoxon signed-rank tests for paired data were applied. To test for differences in survey responses by study arms, Fisher's exact tests were applied for categorical variables, and exact Wilcoxon rank sum tests were applied for continuous variables. All reported p-values are two-sided and were considered significant at a Type I error level of 0.05 . All analyses were performed with $\mathrm{R}$ software, with statistical tests using the stats and coin packages in $\mathrm{R}$.

\section{Results}

\section{Participant Recruitment}

A total of 158 participants were recruited by 17 of 22 participating community pharmacy partners and consented to undergo PGx testing. Pre-testing data were collected and provided by the pharmacists for a total of 151 participants (incomplete pre-testing data were excluded from the dataset for four participants that did not receive physician authorization for testing and three participants from two of the pharmacies that withdrew from study). A chart-review dataset for one participant was not submitted, resulting in an analyzable dataset of 150 participants. Of those 150 participants, $38(25 \%)$ completed both the baseline and follow-up survey.

The number of participants recruited for testing by the 17 pharmacies ranged from one to 20; if excluding the two pharmacies that withdrew mid-study due to low recruitment, the range was five to 20 participants per pharmacy. Forty-five percent of participants were recruited from pharmacies in the control arm (PGx only).

\section{Participant Characteristics}

Based on the chart review data submitted by pharmacists, $59.3 \%$ of participants enrolled and tested were female; the mean age was 61 years and $90.0 \%$ were White (Table 1). Of the 10 drugs for which testing was available, the top three drugs prescribed to participants in the study were Metoprolol (29\%), Citalopram (18\%), and Aripiprazole (13\%). We did not observe any differences by gender or race in participant characteristics by study arms; however, the age of participants was significantly older in the PGx plus MTM arm ( $\mathrm{p}=0.007)$.

Additional data were collected from the pre/post-study survey administered to participants. Fifty (33.3\%) participants completed the baseline survey; as mentioned, 38 (25.3\%) participants completed the follow-up survey (data shown in Table 1). Race was the only significant difference between the demographic characteristics of participants who completed the pre-testing survey only and those who completed both the pre- and post-testing survey (white participants were more likely to complete both the pre- and post-study surveys than non-white participants, $\mathrm{p}=0.014)$. Participants who completed both surveys were mostly female $(63.2 \%), 70$ years or older $(23.7 \%)$, and white $(92.1 \%)$. Fifty-five percent of survey participants were enrolled in the PGx-only study arm. Survey participants received testing from 14 participating pharmacies. Since the survey was completed anonymously, we are not able to link the survey data to the pharmacy data.

Health literacy was assessed by a single question, "How confident are you filling out forms by yourself?": $29(76.3 \%)$ responded extremely, $7(18.4 \%)$ quite a bit, and $2(5.3 \%)$ somewhat (the latter category is considered of limited or marginal health literacy skills). To assess general understanding of pharmacogenetics, participants were asked "How would you describe your understanding of how genes can affect the way you respond to a medicine?": 11 (28.9\%) indicated very well, 16 $(42.1 \%)$ indicated somewhat well, 9 (23.7\%) indicated "a 
little" and $1(2.6 \%)$ responded "not at all" (one declined to answer). Only one participant $(2.6 \%)$ indicated they or someone in their family had previously undergone PGx testing.

\section{Test Ordering Process}

After discussing testing with eligible patients, the pharmacist faxed a test authorization form to the prescriber for patients who consented to testing. Based on the case log notes, $97.5 \%$ of test authorization forms were signed and returned by the prescriber. Twenty-seven percent $(41 / 150)$ required at least one reminder and seven percent (11/150) required two reminders. The average length of time between the date the form was faxed to the prescriber and the date that the specimen was sent to the testing laboratory was 29 days (range: 1-214) (note: we did not request the date for when the signed authorization form was returned). In 10 cases, from two pharmacies, a second sample collection was requested due to insufficient DNA from the original specimen.

\section{Testing-Related Medication Changes}

Based on the logbook data submitted by the pharmacist for each participant, a medication change was reported to have been made based on the test result in $8.7 \%$ of cases $(13 / 150)$. In seven cases (4.7\%), an alternative medication was prescribed and in six cases $(4.0 \%)$, the dosing was changed. The most common medication for which a change was made was metoprolol (7), followed by citalopram (4), warfarin (1), and simvastatin (1). There was no significant difference with respect to study arm if a medication change was made. Regarding measures of medication adherence data submitted by the pharmacist, we observed no significant difference between participants enrolled in the PGx test only and the PGx plus MTM arm for either the proportion of days covered or the medication possession ratio. In comparison to control patients (no intervention), matched by age, race, and eligible medication for PGx testing for each enrolled participant, we did not observe any significant difference in proportion of days covered nor medication possession ratio.

\section{Participants' Self-Reported Medication Adherence}

Before testing, 32 participants (84.2\%) agreed or strongly agreed with the statement that they took all of their medication in the past seven days. No significant change in behavior was observed post-testing $(78.9 \% ; \mathrm{p}=0.72)$. For posttesting, participants $\geq 50$ years of age were more likely to report that they took all of their medications $(p=0.04)$.

We further analyzed the reasons participants' might not take all doses of their medication. For both pre-testing and post-testing, cost was the top reason noted for not taking medication as prescribed, followed by too busy, traveling or running out of medication. In addition, in the posttesting survey, concern about taking medications for the rest of their life was reported as a top reason.

\section{Attitudes Toward Medications}

We used the BMQ to assess participants' attitudes toward medications. Of the four subscales, overall, participants' beliefs in medications did not change for three subscales (harm, necessity, and concern) before and after testing and no significant differences were observed between study arms (Table 2). The exception was the score for the general overuse subscale, which assessed participants' beliefs regarding medication over-prescription by health providers. This score significantly increased after testing $(p=0.014)$. We explored these findings by study arm and observed a significant change only for the general overuse subscale in the PGX only study arm $(\mathrm{p}=0.01)$.

Table 2 Scores of Beliefs About Medication Questionnaire Subscales by Study Arm

\begin{tabular}{|l|c|c|c|c|}
\hline \multirow{2}{*}{ BMQ Scale (Score Range) } & \multicolumn{2}{|c|}{ Baseline Mean (Range) } & \multicolumn{2}{c|}{ Follow-Up Mean (Range) } \\
\cline { 2 - 5 } & PGx Only (N=2 I) & PGx+MTM (N=I7) & PGx Only (N=2I) & PGx+MTM (N=I7) \\
\hline General Overuse (4-19) & $11.5(7-17)$ & $11.7(4-18)$ & $12.6(9-19)^{*}$ & $12.2(4-19)$ \\
General Harm (4-13) & $8.05(4-12)$ & $7.53(4-13)$ & $8.05(5-12)$ & $7.4 \mid(4-12)$ \\
Specific-Necessity (9-25) & $16.7(10-25)$ & $18.2(I I-25)$ & $17.8(9-25)$ & $18.3(10-25)$ \\
Specific- Concern (5-22) & $13.3(5-20)$ & $11.5(5-22)$ & $14.2(7-20)$ & $12.6(6-20)$ \\
Specific- Necessity vs.- Concern (-5-19) & $3.38(-5-12)$ & $6.7 I(-3-18)$ & $3.57(-5-15)$ & $5.7 \mid(-2-19)$ \\
\hline
\end{tabular}

Note: *Significant difference post-testing. 


\section{Satisfaction with PGx Testing and Pharmacist Interactions}

Almost all participants (97\%) indicated that they were very satisfied with the amount of time the pharmacist spent explaining the test results; no significant difference by arm was observed. Eighty-seven percent were very satisfied with how well the pharmacist explained the test results and if any changes needed to be made to your medication based on the result; four participants indicated they were somewhat satisfied.

When asked to recall the phenotypic result (eg, poor metabolizer) for each of the five pharmacogenes (CYP2C19, CYP2C9, CYP2D6, SLCO1B1, and VKORC1) for which they were tested, $26.3 \%$ could not recall or were unsure of the results of one or more of the five genes. Three participants (7.9\%) could not recall the result of any of the five genes, all of which were in the PGx only arm. Sixty-two percent of participants in the PGx only arm could recall all five genes compared to $88 \%$ in the PGx plus MTM arm $(\mathrm{p}=0.14)$. However, participants in the PGx plus MTM arm were significantly more likely to recall a higher number of genes than participants in the PGx only arm $(\mathrm{p}=0.04)$. There is no way to know if participants used the test report to answer the survey questions. As the surveys were anonymized and we did not have access to the test results, we were unable to confirm the accuracy of their recall. The likelihood of recalling the results for all genes was associated with education level $(p<0.001)$. Furthermore, the majority $(73 \%)$ did not recall any recommendation given by the pharmacist (though no recommendation may have been warranted depending on specific medication use and test report).

In the post-testing survey, after learning their results, all participants indicated that they would have taken the test in the first place; $71.1 \%$ indicated they would definitely still have taken the test and $28.9 \%$ indicted they probably would (no significant difference by intervention arms). If prescribed a new drug in the future and offered another PGx test, $71 \%$ indicated that they would definitely take the test and $21 \%$ would probably take the test. No significant difference between study arm was observed $(\mathrm{p}=0.17)$.

Overall, just more than half of participants (20/38; $52.6 \%$ ) indicated their knowledge of the PGx results and potential changes to their prescription definitely improved their confidence about the safety and/or effectiveness of their medication, with an additional 34.2\% indicated it somewhat improved their confidence, though no significant differences were observed between study arms. Furthermore, no significant difference between study arms was observed with respect to participants' view of whether the time spent with the pharmacist was worthwhile $(\mathrm{p}=0.20)$ (Table 3).

Overall, participants reported a high level of satisfaction with their PGx testing experience (97.4\%). In particular, participants reported a high level of satisfaction with the pharmacist for addressing questions about medications or testing (97.4\%), for explaining their medications in an

Table 3 Participant Responses Regarding New Information and Value of Time Spent with Pharmacist per Study Arm

\begin{tabular}{|l|l|l|l|}
\hline & $\begin{array}{l}\text { PGx-Only Study Arm } \\
\text { (n=2I) }\end{array}$ & $\begin{array}{l}\text { PGx + MTM Arm } \\
\text { (n=I7) }\end{array}$ \\
\hline $\begin{array}{l}\text { Did you learn any new information about the drugs you are currently } \\
\text { taking? }\end{array}$ & $\begin{array}{l}\text { Yes, Definitely: } 6 \\
\text { Yes, Somewhat: } 6 \\
\text { No, not really: } 9 \\
\text { No, definitely not: } 0\end{array}$ & $\begin{array}{l}\text { Yes, Definitely: } 8 \\
\text { Yes, Somewhat: I } \\
\text { No, not really: } 8 \\
\text { No, definitely not: } 0\end{array}$ \\
\hline $\begin{array}{l}\text { Did you learn any tips to help you remember to take your drugs as } \\
\text { prescribed? }\end{array}$ & $\begin{array}{l}\text { Yes, Definitely: } 6 \\
\text { Yes, Somewhat: } 3 \\
\text { No, not really: } 9\end{array}$ & $\begin{array}{l}\text { Yes, Definitely: } 3 \\
\text { Yes, Somewhat: I } \\
\text { No, definitely not: } 3\end{array}$ & $\begin{array}{l}\text { No, not really: II } \\
\text { No, definitely not: } 2\end{array}$ \\
\hline Did you feel your time spent with the pharmacist was worthwhile? & $\begin{array}{l}\text { Yes, Definitely: } 16 \\
\text { Yes, Somewhat: } 5 \\
\text { No, not really: } 0 \\
\text { No, definitely not: } 0\end{array}$ & $\begin{array}{l}\text { Yes, Definitely: } 16 \\
\text { Yes, Somewhat: I } \\
\text { No, not really: } 0 \\
\text { No, definitely not: } 0\end{array}$ \\
\hline
\end{tabular}

Note: The p-values in column 4 correspond to analysis of the distribution of the response categories between study arms. 
Table 4 Psychological Responses to Testing in the Post-Testing Survey. P-values Calculated by Comparing Responses of Each Question (Grouped as Never/Rarely, and Sometimes/Often) Between Study Arms

\begin{tabular}{|c|c|c|c|c|c|}
\hline & \multicolumn{2}{|c|}{$\begin{array}{l}\text { PGx-Only Arm } \\
(n=21)\end{array}$} & \multicolumn{2}{|c|}{$\begin{array}{l}\text { PGx Plus MTM Study } \\
(n=17)\end{array}$} & \multirow[b]{2}{*}{ P-value } \\
\hline & $\begin{array}{l}\text { Neverl } \\
\text { Rarely }\end{array}$ & $\begin{array}{l}\text { Sometimes/ } \\
\text { Often }\end{array}$ & $\begin{array}{l}\text { Never/ } \\
\text { Rarely }\end{array}$ & $\begin{array}{l}\text { Sometimes/ } \\
\text { Often }\end{array}$ & \\
\hline Felt upset about my test result & 20 & I & 16 & I & I \\
\hline Felt sad about my test result & 20 & I & 16 & I & I \\
\hline Felt anxious or nervous about my test result & 19 & 2 & 15 & 2 & 1 \\
\hline Felt guilty about my test result & 21 & 0 & 17 & 0 & NA \\
\hline Felt relieved about my test result & 9 & 12 & 5 & 12 & 0.51 \\
\hline Felt happy about my test result & 7 & 14 & 3 & 14 & 0.46 \\
\hline Felt a loss of control & 20 & 1 & 16 & I & 1 \\
\hline Had problems enjoying life because of my test results & 21 & 0 & 16 & I & 0.45 \\
\hline Worried about my risk of having a side effect or my medication not working & 17 & 4 & 13 & 4 & I \\
\hline $\begin{array}{l}\text { Uncertain about what my test result means about how I will respond to } \\
\text { medications }\end{array}$ & 17 & 4 & 12 & 5 & 0.70 \\
\hline $\begin{array}{l}\text { Uncertain about what my test result means for my child(ren) and/or family's } \\
\text { response to medications }\end{array}$ & 21 & 0 & 14 & 3 & 0.08 \\
\hline Had difficulty making decisions about my medications & 19 & 2 & 16 & I & I \\
\hline Understood clearly my choices for prevention or early detection of side effects & 10 & 11 & I & 16 & 0.01 \\
\hline $\begin{array}{l}\text { Felt frustrated that there are no definite guidelines to prevent side effects or } \\
\text { medications that do not work for me based on the test results }\end{array}$ & 17 & 4 & 12 & 5 & 0.70 \\
\hline Thought about how my test results affected my work or family life & 21 & 0 & 14 & 3 & 0.08 \\
\hline $\begin{array}{l}\text { Felt concerned about how my test results will affect my health insurance } \\
\text { coverage }\end{array}$ & 19 & 2 & 15 & 2 & 1 \\
\hline Had difficulty talking about my test results with family members & 20 & I & 16 & I & 1 \\
\hline Felt that my family was supportive during the testing process & 9 & 12 & 1 & 16 & 0.01 \\
\hline Felt satisfied with my family communication about my test result & 8 & 13 & 1 & 16 & 0.03 \\
\hline Worried that the testing process has brought about conflict within my family & 21 & 0 & 17 & 0 & NA \\
\hline Felt regret about getting my test results & 21 & 0 & 17 & 0 & NA \\
\hline $\begin{array}{l}\text { Worried about the possibility of my children having side effects or being } \\
\text { prescribed a drug not likely to work for them* }\end{array}$ & 12 & 5 & 9 & 3 & I \\
\hline Felt guilty about possibly passing on a pharmacogenetic risk to my children* & 15 & 2 & 10 & 2 & I \\
\hline
\end{tabular}

Note: *These questions were only asked of participants who indicated that they had children.

understandable manner $(94.7 \%)$, for resolving any medication problems $(84.2 \%)$, and for diet and exercise advice given $(63.2 \%)$. No significant differences in participants' level of satisfaction were observed between study arms.

\section{Psychological Impact of PGx Testing and Information-Sharing}

The majority of participants overall $(68.4 \%)$ shared their results with either a doctor, a spouse/partner, other family 
members, or other people at the time of the post-testing survey. Twenty-six percent shared their results with more than one person. No significant difference between study arms was observed with respect to if participants shared the results or the number of people the results were shared with.

Sixty-three percent of participants overall indicated they felt relieved (often/sometimes) and 73.7\% reported feeling happy (often/sometimes) about their test results (Table 4). Overall, $71.1 \%$ of participants indicated that they felt that they often/sometimes understood their choices for prevention or early detection of side effects. However, significantly more participants in the PGx plus MTM arm indicated that they often/sometimes understood clearly the choices for prevention or early detection of side effects compared to participants in the PGx only arm $(\mathrm{p}=0.01)$. Participants in the PGx plus MTM arm were also significantly more likely to indicate they had family support during the testing process $(p=0.012)$ as well as satisfaction with their family communication or discussion about their test result $(\mathrm{p}=0.026)$.

We observed no significant difference in concerns and psychosocial issues associated with PGx testing between study arms using the MICRA survey instrument (mean(sd) for the PGx-Only Arm = 16.57 (7.59) and for PGx plus MTM arm = $16.41(15.84)$; $p$-value $=0.1489)$. Among the negative impacts reported after receiving the PGx test results, $23.7 \%$ overall were sometimes uncertain about what their test result means about how they will respond to medications. Twenty-one percent were worried about their risk of having a side effect or their medication not working. Of the 29 participants who had children, eight $(27.6 \%)$ overall reported that they were worried about the possibility of their children having side effects or being prescribed a drug not likely to work for them.

\section{Discussion}

The successful delivery of PGx testing in a community pharmacy setting pivots on at least three major stakeholders, namely the patient, the pharmacist, and the prescriber. With the novelty of PGx testing for all three groups, it is critical to consider the attitudes of each group as well as the setting in which PGx testing may be successfully delivered. In this study conducted in a community pharmacy setting, we evaluated the delivery process, outcomes, and pharmacists' and patients' experiences with PGx testing. Overall, we found positive experiences for both patient and pharmacist participants with the provision of PGx testing in this setting.
However, the addition of MTM to PGx testing yielded limited benefit with respect to participant comprehension or attitudes toward medications. No change to medications based on PGx testing or medication adherence overall was observed.

Despite the novel experience of receiving PGx testing in a pharmacy setting, likely the first time for many, all participants indicated they would be very or somewhat likely to have PGx testing for another medication if indicated. The positive patient experiences reported in this study align with other reported experiences and positive patient/public attitudes regarding PGx testing and willingness to have testing. Participants reported high satisfaction with the delivery of PGx testing and pharmacists' services, suggesting this could be an effective strategy for PGx testing.

The rather limited impact of MTM in conjunction with PGx testing may be due to differences in pharmacist experience, the complexity of patients' medication histories, and the type of test results (normal/mixed results). If the benefit of MTM to the use and understanding of PGx test results is limited in a general population as demonstrated here, we suggest that MTM in combination with PGx testing may yield more benefits if offered to those patients reporting medication problems and/or taking a higher number of medications. However, we did observe that participants in the PGx plus MTM arm were significantly more likely to recall a higher number of genes than participants in the PGx only arm. Thus, the additional time with the pharmacist may have been helpful for some patients, but other educational resources or communication strategies are still likely needed since $25 \%$ of the study population could not recall their test results. Patient unfamiliarity with PGx testing, complex scientific concepts, and lack of relevance to current medication usage contribute to the lack of understanding and the challenges of effective communication. We and others have developed and evaluated patient educational tools to facilitate patient-provider communication about PGx testing. PGx educational materials included print, video, and digital-format that can be displayed on a tablet and be used when discussing purpose of testing, genotypes, phenotypes and the clinical significance for treatment.

With respect to the pharmacist burden, on average, there were seven tasks carried out, with the majority occurring during the pre-testing phase. The most timeconsuming part may have been making follow-up calls to both patients and providers. For almost a quarter of 
patients who consented to testing, pharmacists had to follow-up with the prescriber about the test authorization request, and seven percent had to follow up twice. Because the time required for various tasks was not consistently reported, we were not able to accurately assess the overall time required to deliver PGx testing. To facilitate the delivery of PGx testing by pharmacists, more professional resources at the point-of-care may be helpful. While we provided a suite of patient educational aides, additional resources for providers as well as resources accessible to patients before and after their pharmacy visit could help alleviate the burden on pharmacists. In addition, a longterm relationship between pharmacists and prescribers may improve acceptance of recommendations to order PGx testing as well as better acceptance of results, and confidence that testing may be used by the pharmacist to ensure prescriptions are compatible with their genotype. This statement also holds true for the relationship between patients and their pharmacist.

Apart from our exploration of the feasibility of delivering PGx testing within a community setting, we assessed the impact on patient outcomes based on pharmacy records and self-reported survey responses. In comparison to the control population matched by age, race, and medication for each enrolled participant, we did not observe any significance difference in proportion of days covered nor medication possession ratio in the intervention arms. Other studies have reported a high number of treatment recommendations from a combined MTM plus PGx program. Many factors could account for this observation, including low number of abnormal test results, length of time on treatment, and patient or provider reluctance to modify prescriptions. Similar to our other study in a primary care setting, there were also no significant changes in participant attitudes regarding perceived harms or perceived necessity of medications. We speculate that the significant increase in score for perceived overuse of medications may be influenced by the older age of participants, as $42 \%$ were aged 60 years and older, and the likely higher number of medications. We also did not observe any differences in medication adherence, likely due to the already high level of reported adherence. A positive impact of PGx testing on adherence has been reported in studies for statins.

We should note some limitations of the study. In particular, the population size and limited response rate were key limitations. The invitation to participants to complete surveys was provided by the community pharmacist, and it is possible that not all eligible participants received it. With the relatively small number of participants, the results may not be applicable to the entire study population or other regions. In particular, the older study population may not be representative of a more evenly distributed study population with respect to medication use and experience and memory recall ability. Other potential limitations may be due to the choice of survey instruments, eg, single question literacy assessment, participant use of their test reports or other materials to complete the online survey, and participant use of other pharmacies or pharmacy benefit programs. In addition, as the study was based in independent community pharmacies in North Carolina, consumer and pharmacist demographics may differ compared to other regions, thereby limiting the generalizability of the dataset.

With the growing suite of health services offered by pharmacists in community pharmacy and the high level of trust from patients, this study demonstrates that the introduction of PGx testing in this setting may be feasible and integrated into community practices without traditional billing and practice structures like

MTM. The lack of observed significant findings between MTM and non-MTM arms suggests that PGx testing and return of test results can be deployed at community pharmacies in clinical services that are more targeted towards specific medications rather than the comprehensive medication review. The delivery of PGx testing in a community pharmacy setting was accepted by patients and feasible for pharmacists, although further investigation into the delivery model and prescriber and patient resources is needed.

\section{Data Sharing Statement}

The raw data set used for this study is offered by the corresponding author upon reasonable request.

\section{Acknowledgment}

This study was funded by the US National Institutes of Health (R01GM081416).

\section{Disclosure}

Susanne B Haga reports grants from US National Institutes of Health, during the conduct of the study. Dr Deepak Voora reports grants from $\mathrm{NIH}$, during the conduct of the study; personal fees from Optum, outside the submitted work. The authors report no other conflicts of interest in this work. 


\section{References}

1. Scott SA, Scott ER, Seki Y, et al. Development and analytical validation of a 29 gene clinical pharmacogenetic genotyping panel: multi-ethnic allele and copy number variant detection. Clin Transl Sci. 2020. doi:10.1111/cts. 12844

2. Van Driest SL, Shi Y, Bowton EA, et al. Clinically actionable genotypes among 10,000 patients with preemptive pharmacogenomic testing. Clin Pharmacol Ther. 2014;95(4):423-431. doi:10.1038/ clpt.2013.229

3. Relling MV, Evans WE. Pharmacogenomics in the clinic. Nature. 2015;526(7573):343-350. doi:10.1038/nature15817

4. Williams MS. Early lessons from the implementation of genomic medicine programs. Annu Rev Genomics Hum Genet. 2019;20 (1):389-411. doi:10.1146/annurev-genom-083118-014924

5. Manolio TA, Chisholm RL, Ozenberger B, et al. Implementing genomic medicine in the clinic: the future is here. Genet Med. 2013;15 (4):258-267. doi:10.1038/gim.2012.157

6. Weitzel KW, Elsey AR, Langaee TY, et al. Clinical pharmacogenetics implementation: approaches, successes, and challenges. $\mathrm{Am} \mathrm{J} \mathrm{Med}$ Genet C. 2014;166(1):56-67. doi:10.1002/ajmg.c.31390

7. Dunnenberger HM, Biszewski M, Bell GC, et al. Implementation of a multidisciplinary pharmacogenomics clinic in a community health system. Am J Health Syst Pharm. 2016;73(23):1956-1966. doi:10.2146/ajhp160072

8. O'donnell PH, Bush A, Spitz J, et al. The 1200 patients project: creating a new medical model system for clinical implementation of pharmacogenomics. Clin Pharmacol Ther. 2012;92(4):446-449. doi:10.1038/clpt.2012.117

9. Dunnenberger HM, Crews KR, Hoffman JM, et al. Preemptive clinical pharmacogenetics implementation: current programs in five US medical centers. Annu Rev Pharmacol Toxicol. 2015;55(1):89-106. doi:10.1146/annurev-pharmtox-010814-124835

10. Van Der Wouden CH, Bank PCD, Özokcu K, Swen JJ, Guchelaar HJ. Pharmacist-initiated pre-emptive pharmacogenetic panel testing with clinical decision support in primary care: record of pgx results and real-world impact. Genes (Basel). 2019;10(6):416. doi:10.3390/ genes 10060416

11. Swen JJ, Van Der Straaten T, Wessels JA, et al. Feasibility of pharmacy-initiated pharmacogenetic screening for CYP2D6 and CYP2C19. Eur J Clin Pharmacol. 2012;68(4):363-370. doi:10.1007/s00228-011-1130-4

12. Arwood MJ, Dietrich EA, Duong BQ, et al. Design and early implementation successes and challenges of a pharmacogenetics consult clinic. J Clin Med. 2020;9(7):2274. doi:10.3390/jcm9072274

13. Liko I, Corbin L, Tobin E, Aquilante CL, Lee YM. Implementation of a pharmacist-provided pharmacogenomics service in an executive health program. Am J Health Syst Pharm. 2021;78(12):1094-1103. doi:10.1093/ajhp/zxab137

14. Brown JT, Gregornik D, Kennedy MJ. The role of the pediatric pharmacist in precision medicine and clinical pharmacogenomics for children. J Pediatr Pharmacol Ther. 2018;23(6):499-501. doi:10.5863/1551-6776-23.6.499

15. Caraballo PJ, Hodge LS, Bielinski SJ, et al. Multidisciplinary model to implement pharmacogenomics at the point of care. Genet Med. 2017;19(4):421-429. doi:10.1038/gim.2016.120

16. Wang YT, Merl MY, Yang J, Zhu ZX, Li GH. Opportunities for pharmacists to integrate pharmacogenomics into clinical practice. Pharmacogenomics J. 2020;20(2):169-178. doi:10.1038/s41397019-0119-8

17. Roederer M, Van Riper M, Valgus J, Knafl G, Mcleod H. Knowledge, attitudes and education of pharmacists regarding pharmacogenetic testing. Per Med. 2012;9(1):19-27. doi:10.2217/pme.11.87
18. Bank PC, Swen JJ, Guchelaar HJ. A nationwide survey of pharmacists' perception of pharmacogenetics in the context of a clinical decision support system containing pharmacogenetics dosing recommendations. Pharmacogenomics. 2017;18(3):215-225. doi:10.2217/ pgs-2016-0138

19. Alexander KM, Divine HS, Hanna CR, Gokun Y, Freeman PR. Implementation of personalized medicine services in community pharmacies: perceptions of independent community pharmacists. J Am Pharm Assoc (2003). 2014;54(5):510-517. doi:10.1331/ JAPhA.2014.13041

20. Accreditation Council for Pharmacy Education. Accreditation standards and guidelines: professional program in pharmacy leading to the doctor of pharmacy degree; 2016. Available from: https://www. acpe-accredit.org/pdf/Standards2016FINAL.pdf. Accessed June 28, 2021.

21. Roederer MW, Kuo GM, Kisor DF, et al. Pharmacogenomics competencies in pharmacy practice: a blueprint for change. $J$ Am Pharm Assoc (2003). 2017;57(1):120-125. doi:10.1016/j.japh.2016.08.014

22. Haga SB, Moaddeb J. Pharmacogenomics courses in pharmacy school curricula. Pharmacogenomics. 2019;20(9):625-630. doi:10.2217/pgs-2019-0024

23. Cavallari LH, Overholser BR, Anderson D, et al. Recommended basic science foundation necessary to prepare pharmacists to manage personalized pharmacotherapy. Pharmacotherapy. 2010;30(6):626. doi:10.1592/phco.30.6.626

24. Formea CM, Nicholson WT, Vitek CR, et al. Implementation of a pharmacogenomics education program for pharmacists. Am $J$ Health Syst Pharm. 2018;75(23):1939-1946. doi:10.2146/ ajhp170771

25. Marcinak R, Paris M, Kinney SRM. Pharmacogenomics education improves pharmacy student perceptions of their abilities and roles in its use. Am J Pharm Educ. 2018;82(9):6424. doi:10.5688/ajpe6424

26. Crown N, Sproule BA, Luke MJ, Piquette-Miller M, Mccarthy LM. A continuing professional development program for pharmacists implementing pharmacogenomics into practice. Pharmacy (Basel). 2020;8(2). doi:10.3390/pharmacy 8020055

27. Ferreri SP, Greco AJ, Michaels NM, et al. Implementation of a pharmacogenomics service in a community pharmacy. $J \mathrm{Am}$ Pharm Assoc. 2014;54(2):172-180. doi:10.1331/JAPhA.2014.13033

28. O'connor SK, Ferreri SP, Michaels NM, et al. Exploratory planning and implementation of a pilot pharmacogenetic program in a community pharmacy. Pharmacogenomics. 2012;13(8):955-962. doi:10.2217/pgs.12.67

29. Allen Lapointe NM. Challenges to integrating pharmacogenetic testing into medication therapy management. Pharmacogenomics. 2015;21(4):346-352.

30. Gregory PA, Austin Z. How do patients develop trust in community pharmacists? Res Social Adm Pharm. 2021;17(5):911-920. doi:10.1016/j.sapharm.2020.07.023

31. Gregory PAM, Austin Z. Understanding the psychology of trust between patients and their community pharmacists. Can Pharm J. 2021;154(2):120-128. doi:10.1177/1715163521989760

32. Lopez T, Nuffer W. Impact and sustainability of a 10-year community pharmacy disease management service. Innov Pharm. 2021;12(1):13. doi:10.24926/iip.v12i1.3630

33. Fera T, Bluml BM, Ellis WM. Diabetes ten city challenge: final economic and clinical results. J Am Pharm Assoc (2003). 2009;49 (3):383-391. doi:10.1331/JAPhA.2009.09015

34. Brown JVE, Walton N, Meader N, et al. Pharmacy-based management for depression in adults. Cochrane Database Syst Rev. 2019;12 (12):Cd013299. doi:10.1002/14651858.CD013299.pub2

35. Joseph T, Hale GM, Moreau C, Kourtakis SL, Wolowich WR. impact of a pharmacy-led transitions of care program within a primary care-based accountable care organization. Sr Care Pharm. 2021;36 (6):311-316. doi:10.4140/TCP.n.2021.311 
36. Fazel MT, Bagalagel A, Lee JK, Martin JR, Slack MK. Impact of diabetes care by pharmacists as part of health care team in ambulatory settings: a systematic review and meta-analysis. Ann Pharmacother. 2017;51(10):890-907. doi:10.1177/ 1060028017711454

37. Ramos H, Pardo J, Sánchez R, et al. Pharmacist-physician interprofessional collaboration to promote early detection of cognitive impairment: increasing diagnosis rate. Front Pharmacol. 2021;12:579489. doi:10.3389/fphar.2021.579489

38. Haga SB, Moaddeb J, Mills R, Voora D. Assessing feasibility of delivering pharmacogenetic testing in a community pharmacy setting. Pharmacogenomics. 2017;18(4):327-335. doi:10.2217/pgs-2016-0175

39. Horne R, Weinman J. Patients' beliefs about prescribed medicines and their role in adherence to treatment in chronic physical illness. J Psychosom Res. 1999;47(6):555-567. doi:10.1016/S0022-3999(99) 00057-4

40. Voils CI, Maciejewski ML, Hoyle RH, et al. Initial validation of a self-report measure of the extent of and reasons for medication nonadherence. Med Care. 2012;50(12):1013-1019. doi:10.1097/ MLR.0b013e318269e121

41. Cella D, Hughes C, Peterman A, et al. A brief assessment of concerns associated with genetic testing for cancer: the Multidimensional Impact of Cancer Risk Assessment (MICRA) questionnaire. Health Psychol. 2002;21(6):564-572. doi:10.1037/0278-6133.21.6.564

42. Haga SB. Evaluation of a pharmacogenetic educational toolkit for community pharmacists. Expert Rev Mol Diagn. 2016;17 (14):1491-1502.

43. Wallace LS, Rogers ES, Turner LW, Keenum AJ, Weiss BD. Suitability of written supplemental materials available on the Internet for nonprescription medications. Am J Health Syst Pharm. 2006;63(1):71-78. doi:10.2146/ajhp050071

44. Haga SB, Mills R, Moaddeb J, et al. Patient experiences with pharmacogenetic testing in a primary care setting. Pharmacogenomics. 2016;17(15):1629-1636. doi:10.2217/pgs-2016-0077

45. Breaux S, Desrosiers FAD, Neira M, Sinha S, Nislow C. Pharmacogenomics at the point of care: a community pharmacy project in British Columbia. $J$ Pers Med. 2020;11(1):11. doi:10.3390/jpm11010011

46. Haga SB, Moaddeb J, Mills R, et al. Incorporation of pharmacogenetic testing into medication therapy management. Pharmacogenomics. 2015;16(17):1931-1941. doi:10.2217/ pgs. 15.124
47. Bright D, Worley M, Porter BL. Patient perceptions of pharmacogenomic testing in the community pharmacy setting. Res Social Adm Pharm. 2020;17(4):744-749. doi:10.1016/j.sapharm.2020.06.022

48. Mukherjee C, Sweet KM, Luzum JA, et al. Clinical pharmacogenomics: patient perspectives of pharmacogenomic testing and the incidence of actionable test results in a chronic disease cohort. Per Med. 2017;14(5):383-388. doi:10.2217/pme-2017-0022

49. Olson JE, Rohrer Vitek CR, Bell EJ, et al. Participant-perceived understanding and perspectives on pharmacogenomics: the mayo clinic RIGHT protocol (right drug, right dose, right time). Genet Med. 2017;19(7):819-825. doi:10.1038/gim.2016.192

50. Mills R, Haga SB. Qualitative user evaluation of a revised pharmacogenetic educational toolkit. Pharmgenomics Pers Med. 2018;11:139-146. doi:10.2147/PGPM.S169648

51. Truong TM, Lipschultz E, Danahey K, et al. Assessment of patient knowledge and perceptions of pharmacogenomics before and after using a mock results patient web portal. Clin Transl Sci. 2020;13 (1):78-87. doi:10.1111/cts.12681

52. Asiedu GB, Finney Rutten LJ, Agunwamba A, et al. An assessment of patient perspectives on pharmacogenomics educational materials. Pharmacogenomics. 2020;21(5):347-358. doi:10.2217/pgs-2019-0175

53. Romagnoli KM, Boyce RD, Empey PE, Adams S, Hochheiser H. Bringing clinical pharmacogenomics information to pharmacists: a qualitative study of information needs and resource requirements. Int $J \quad$ Med Inform. 2016;86:54-61. doi:10.1016/j. ijmedinf.2015.11.015

54. Brown JT, Macdonald D, Yapel A, et al. Integrating pharmacogenetic testing via medication therapy management in an outpatient family medicine clinic. Pharmacogenomics. 2021;22(4):203-212. doi:10.2217/pgs-2020-0178

55. Charland SL, Agatep BC, Herrera V, et al. Providing patients with pharmacogenetic test results affects adherence to statin therapy: results of the additional KIF6 risk offers better adherence to statins (AKROBATS) trial. Pharmacogenomics J. 2014;14(3):272-280. doi:10.1038/tpj.2013.27

56. Wang J, Ford LJ, Wingate L, et al. Effect of pharmacist intervention on herpes zoster vaccination in community pharmacies. $J$ Am Pharm Assoc (2003). 2013;53(1):46-53. doi:10.1331/JAPhA.2013.12019

57. Tucker R, Stewart D. Why people seek advice from community pharmacies about skin problems. Int $J$ Pharm Pract. 2015;23 (2):150-153. doi:10.1111/ijpp.12126
Pharmacogenomics and Personalized Medicine

\section{Publish your work in this journal}

Pharmacogenomics and Personalized Medicine is an international, peer-reviewed, open access journal characterizing the influence of genotype on pharmacology leading to the development of personalized treatment programs and individualized drug selection for improved safety, efficacy and sustainability. This journal is indexed on the American Chemical Society's Chemical Abstracts Service (CAS). The manuscript management system is completely online and includes a very quick and fair peer-review system, which is all easy to use. Visit http://www.dovepress.com/testimonials.php to read real quotes from published authors. 